\title{
A Survey of Authentic Teaching in Secondary Math and Science Classrooms
}

\author{
Tamy L. Fry ${ }^{1}$, Teri Reed Rhoads ${ }^{1}$, Mark Nanny ${ }^{2}$ and Mary John O'Hair ${ }^{3}$ \\ The University of Oklahoma \\ School of Industrial Engineering ${ }^{1}$ \\ School of Civil Engineering and Enviro nmental Science ${ }^{2}$ \\ Center for Educational and Community Renewal ${ }^{3}$
}

\begin{abstract}
The Authentic Teaching Alliance (ATA) is a project funded through the National Science Foundation GK-12 program in which University of Oklahoma Fellows from engineering and education disciplines team with local teachers to design, implement, and assess authentic, inquiry-based activities to teach secondary science and mathematics. This paper discusses the adaptation and implementation of an instrument to survey the students' science and math classroom experiences and to assess whether the ATA activities had a measurable effect on the students' desire to learn. The search for a validated instrument to serve our needs led to a survey developed in the Netherlands by Roelofs and Terwel $(1997)^{1}$. The survey was modified to elicit information about the existing state of the science and math classroom environment as perceived by the teachers and the students. Pre-post implementation was utilized to help us evaluate the success of the project by comparing responses before and after implementation of the ATA activities.
\end{abstract}

\section{The Authentic Teaching Alliance}

In recent years, the nation's educators have expressed growing concern as they witness the dwindling numbers of students entering math, science, and engineering fields. According to the National Science Foundation (NSF), enrollment in engineering dropped by more than 20 percent between 1983 and 1999, and continues to decline ${ }^{2}$. Interest in math and science seems to be at an all-time low. The National Center for Education Statistics (2002) reported that attitudes toward math have been shown to decline from grade eight to grade twelve for the majority of students, and are generally more negative for females ${ }^{3}$. This is also reflected in the national math and science performance figures reported in the Third International Mathematics and Science Study-Repeat (TIMSS-R) conducted in 1999, which showed a drop in performance from the eighth grade to the twelfth grade 4 . Internationally, the math and science achievement scores for students in the United States were significantly lower than 14 countries, including Singapore, the Republic of Korea, Chinese Taipei, Hong Kong (SAR), Japan, Flemish Belgium, Australia, the Netherlands, the Slovak Republic, Hungary, Canada, Slovenia, the Russian Federation, and Finland.

In response to this looming problem, the NSF Graduate Fellow K-12 (GK-12) program was initiated to attempt to reverse this alarming trend, and to encourage students to consider occupations in math and science-related careers. The Authentic Teaching Alliance (ATA) at the University of Oklahoma was one of 24 projects selected for funding by the NSF GK-12 program 
in 2001. The ATA utilizes a cross-curriculum design that combines the talents of engineering, science, and education professionals to devise new ways to teach math and science to secondary students. The ATA also seeks to reduce the fear and confusion surrounding new technologies, and to build and renew the students' desire to become involved in technological fields. This is accomplished by allowing the students to experience math and science in ways that are exciting and meaningful to them in their everyday lives. The ATA utilizes project teams consisting of an education fellow, a science or engineering fellow (one is an undergraduate fellow and the other one is a graduate fellow), and a participating secondary school teacher to develop and implement relevant, hands-on lessons to teach math and science concepts in the classrooms. The lesson activities are designed to introduce the required curriculum concepts in a fun and interesting manner, to demonstrate the students' potential to understand and enjoy math and science, and to enhance their knowledge about careers in math, science, engineering, and other technical fields.

Beyond bringing their experiences and knowledge into the classroom, the ATA fellows also serve as mentors and role models to the secondary school students. The diverse population of ATA fellows helps demonstrate that science and math degrees are truly within the reach of females, African Americans, Hispanics, American Indians, and other minority students. After selection for participation in the program, the ATA fellows are required to complete an in-depth course of formal training for which they receive college credit. This course was designed to provide the fellows with the educational theory and scientific background necessary to create effective, authentic classroom activities. For a more detailed discussion on the goals and structure of the ATA program and the content and objectives of the ATA course, see Rhoads, Nanny, and O'Hair (2002) ${ }^{5}$.

The ATA program encourages life-long learning, and is designed not only to benefit the secondary students, but all who are involved in the program. It is hoped that the fellows will benefit from their participation by enlightening them to the need to become involved in educational issues and to recognize their ability to meaningfully affect the lives of others. In interviews conducted at the end of the first year, several of the ATA fellows reported that they have begun to consider roles in teaching or other educational pursuits due to their participation of the program. The program supports the participating teachers in their efforts to further their education, to expand their math and science knowledge, and to improve their teaching methods. The program also benefits the teachers by allowing them to develop partnerships with higher education and by creating avenues that provide the m easy access to new information and technology. If the ATA classroom experience is positive, reports of its impact could spread to other students within the schools, and might extend to the friends, families, and even the communities of the students.

\section{Assessing Authentic Teaching Practices in the Classroom}

One of the founding principles upon which the ATA was built is that authentic teaching practices enhance understanding and retention of math and science concepts. Newman \& Associates (1996) studied the impact of authentic teaching in more than 1500 secondary schools. The authors reported that students who experienced authentic, inquiry-based teaching in their classrooms excelled over students who were taught using traditional teaching methods ${ }^{6}$. We believe that the success of the ATA program is directly linked to our use of authentic teaching 
practices. Therefore, we began a search for a validated survey instrument to evaluate the effectiveness of the ATA program in promoting authentic teaching practices in the participating math and science classrooms. We hoped to locate a survey that could be used to compare the state of the teaching environment before and after implementation of the ATA projects to help us evaluate the success of the program with respect to the way it was received and perceived by the students and the educators. Unfortunately, no existing survey was wholly appropriate or sufficient to meet our needs. However, in order to build upon the existing base of knowledge and experience, we decided that the next best option was to adapt one or more surveys to meet our needs.

We ultimately chose a set of survey instruments developed by researchers at the Department of Educational Studies and Center for Research on Cognition and Learning and the Educational Research Institute at Utrecht University in Ljubljana, The Netherlands. The surveys were developed and tested in response to a national push in the Netherlands to improve teaching and encourage authentic teaching methods ${ }^{7}$. A pair of Authentic Pedagogy questionnaires created by Roelofs and Terwel ${ }^{1}$ were designed to elicit information from secondary students relating their experiences with authentic teaching practices. The instruments initially consisted of two separate surveys: one for foreign language (English) courses and one for mathematics courses. A separate teacher's manual was provided with each instrument that contained instructions for administration of the individual questionnaires. The original questionnaires contained excerpts describing a classroom situation that illustrated a characteristic of authentic teaching. The excerpts were followed by questions related to the student's experience with that particular characteristic in their own classroom. Responses to the questions were given on a scale from 1 to 5, with 1 representing 'never', and 5 representing 'very often'. An example of the original format for the student questionnaire is shown in Figure 1. The student questionnaire for the math classrooms contained 23 items, while the questionnaire for the English classrooms consisted of 26 items.

$1=$ never, $2=$ seldom, $3=$ sometimes, $4=$ often, $5=$ very often

\section{Question 5}

In Peter's class students sometimes carry out tasks which are not assigned by the teacher. These tasks are related to English. For instance reading an English book for young students, or completing extra tasks. The teacher encourages the students to do this.

5. In your class, do you ever do tasks which $\quad \begin{array}{llllll}1 & 2 & 3 & 4 & 5\end{array}$ are not assigned by the teacher?

\section{Figure 1. Sample Format of the Authentic Pedagogy Student Questionnaire by Roelofs and Terwel (1997) ${ }^{1}$.}

A similar Authentic Pedagogy questionnaire was developed by Franssen and Roelofs (1997) to assess teachers' attitudes toward and use of authentic teaching practices in their own classrooms $^{8}$. The teacher questionnaire also employed a situation-specific format, and originally contained 67 items designed to evaluate the four characteristics of authentic teaching: construction of knowledge, connection of the knowledge to the students' personal world, value 
beyond the classroom, and encouraging cooperation and communication. Responses to the questions were made on a six-point scale from $1=$ never $/$ fully disagree to $6=$ always $/$ fully agree.

\section{Creation of the ATA Questionnaires}

We obtained versions of the Authentic Pedagogy instruments that had previously been translated from their original Dutch language. Unfortunately, these versions contained numerous grammatical and spelling errors. These errors were corrected being careful not to change the context or meaning of the questions. To reduce the time requirements for the respondents, the questionnaires were modified by removing the sit uational excerpts, as we believed that the questions were clear without them. Also, we did not want to bias the results by leading or limiting the responses to a particular situation that may not apply, thereby changing the respondent's initial reaction. The instructions encouraged the participants to respond spontaneously and as truthfully as possible.

The adapted surveys can be said to be a close paraphrasing of the original questionnaires. However, grammar and sentence structure were changed at times to make the translated questions more readable. For consistency, we changed the format of the items from a mixture of questions and declarative statements to statements only. Further, the numeric coding was dropped to reduce confusion and make it easier to choose the desired response. This was accomplished by replacing the scale numbers with fill-in circles located under the original anchor words. As much as possible, we attempted to retain the original meaning, intention, and character of the questions. The modified questions from the math and English questionnaires were combined to create the ATA Student Experience Survey, which consists of 23 items related to math, and 23 additional items related to science. One item from the math questionnaire and four items from the English questionnaire were excluded from the adapted survey, as they were unnecessary or inappropriate to the ATA classrooms. For example, several of the questions inquired about the amount of time the students spoke using the English language during the class. In each of the original student questionnaires, one of the items was split into two separate items in the ATA student survey. The original items and the resulting adapted items are shown in Figure 2.

Whenever possible, the wording of the questions was oriented such that the most positive response (with respect to demonstrating the use of authentic teaching in the classroom) was 'Very Often'. However, in order to avoid negative wording, and potential negative bias, three questions were included whose most positive response is 'Never'. These questions are numbered 2, 27, and 32 on the ATA student experience questionnaire (see Appendix). For analysis purposes, the ranking of the responses for these three questions was reversed.

The ATA Teacher Experience Survey was created using similar methodology and rationale used in creating the student survey. The authors of the original teacher questionnaire reported that eight of the original questionnaire items were not included in their analysis, therefore these eight items were also excluded from our survey. Four additional items were eliminated because they were repetitive or inappropriate to our study. The resulting 55-item ATA teacher survey is included as an appendix. In an effort to reduce confusion and increase organization, items were 


\section{Original (Math)}

23. During the completion of assignments we are allowed to help one another, when we do not understand the assignment. We do so before we ask the teacher for help.

\section{Original (English)}

10. For homework we have to memorize a list of English words. These words do not appear in a text we just read.

\section{Adapted (Math and Science)}

21. We are allowed to help one another when we do not understand the assignment.

22. Students in my math class help each other before we ask the teacher for help.

29. The science terms that we use appear in the material that we read.

32. We have to memorize lists of science words.
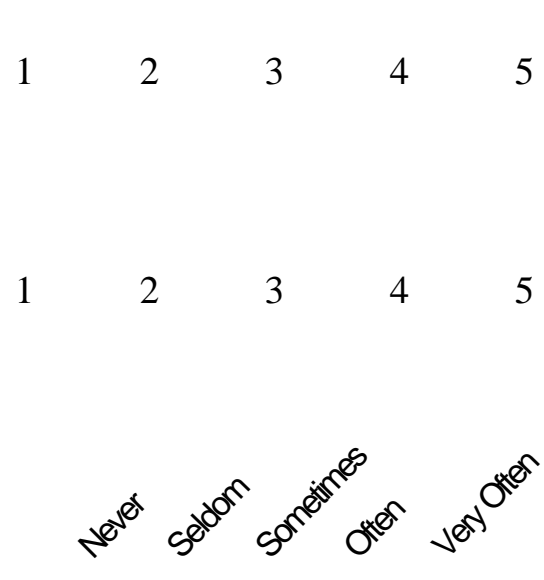

00000

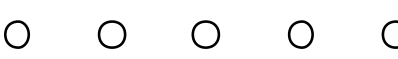

00000

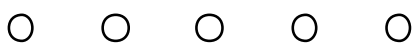

Figure 2. Example Adaptations to Create the ATA Student Experience Survey.

grouped according to their responses. Hence, items 1 through 34 use responses from 'Never' to 'Always', while items 35 through 55 require responses from 'Fully Disagree' to 'Fully Agree'. As with the student experience survey, an attempt was made to word the questions such that the most positive response (indicating the use of authentic teaching methods) was 'Always' or 'Fully Agree'. However, items 45, 51, and 54 did not meet this format, and will therefore be reversescaled for analysis.

Content validity of the adapted ATA surveys was established through review, overseen by Dr. Mary John O'Hair, using authentic pedagogy experts and the Authentic Pedagogy structure. Reliability of the revised instruments was verified by calculating Cronbach's coefficient alpha on the preliminary survey data. Roelofs and Terwel $^{7}$ stated the student questionnaires comprised only one scale that indicated authentic teaching behavior in the classroom. However, since the adapted instrument includes a section of math questions and a set of science questions, these will be analyzed both separately and together. The teacher survey will be evaluated according to the four authentic teaching subscales mentioned above. The face validity of the revised instruments will be tested via exit interviews of the teachers (an exercise completed at the end of each academic year).

\section{Implementation and Analysis}

The Authentic Teaching Alliance Student Experience and Teacher Experience surveys were distributed to the ATA participants at the beginning of the 2002-2003 school year (September 
2002). Each of the respondents were informed of their rights as participants, and provided with parental consent and student assent forms (students), or informed consent forms (teachers). No data will be reported for students who have not returned both permission forms. Identical surveys will be distributed at the end of the school year (May 2003). While the information collected to date can help us to determine the previous classroom experiences of the students and teachers, there is insufficient data collected at this point in time to provide us with information regarding the impact of the ATA program. In order to evaluate the effectiveness of the ATA program, the responses given on the pre- and post-surveys will be compared to determine whether the students and teachers indicate any measurable changes in their experience due the presence of the ATA fellows and curriculum in their classroom.

For analysis, the individual survey responses were scaled by assigning values from 1 (most negative response) to 5 (most positive response). Results of the initial implementation of the ATA student survey for five of the six ATA classrooms are shown in Table 1, which includes the percentage of each response and the average response for each school across all questions. Table 2 contains sample sizes and student demographic data, and also helps to illustrate the diversity in the student populations of the schools participating in the ATA program.

Table 1. Preliminary Student Survey Response Percentages and Overall Averages.

\begin{tabular}{|c|c|c|c|c|c|c|c|c|}
\hline & \multicolumn{5}{|c|}{ Scaled Response } & \multicolumn{3}{|c|}{ Average Response } \\
\hline & $\begin{array}{c}\mathbf{1} \\
\text { (Never) }\end{array}$ & $\begin{array}{c}2 \\
\text { (Seldom) }\end{array}$ & $\begin{array}{c}3 \\
\text { (Sometimes) }\end{array}$ & $\begin{array}{c}4 \\
\text { (Often) }\end{array}$ & $\begin{array}{c}\mathbf{5} \\
\text { (Very Often) }\end{array}$ & Math & Science & Overall \\
\hline School 1 & $23.0 \%$ & $17.0 \%$ & $29.9 \%$ & $14.7 \%$ & $15.3 \%$ & 2.78 & 2.87 & 2.82 \\
\hline School 2 & $29.7 \%$ & $13.5 \%$ & $18.3 \%$ & $25.3 \%$ & $13.1 \%$ & 2.83 & 2.74 & 2.79 \\
\hline School 3 & $22.6 \%$ & $14.9 \%$ & $21.9 \%$ & $18.4 \%$ & $22.3 \%$ & 2.81 & 3.24 & 3.03 \\
\hline School 4 & $25.2 \%$ & $20.8 \%$ & $25.2 \%$ & $16.8 \%$ & $12.0 \%$ & 2.74 & 2.65 & 2.70 \\
\hline School 5 & $14.1 \%$ & $23.2 \%$ & $27.7 \%$ & $22.6 \%$ & $12.4 \%$ & 2.77 & 3.16 & 2.96 \\
\hline
\end{tabular}

Table 2. Preliminary Student Survey Demographics.

\begin{tabular}{|c|c|c|c|c|c|c|c|c|}
\hline & \multirow{2}{*}{$\begin{array}{c}\text { Sample } \\
\text { Size } \\
n\end{array}$} & \multicolumn{2}{|c|}{ Gender } & \multicolumn{5}{|c|}{ Ethnicity } \\
\hline & & Male & Female & White & $\begin{array}{c}\text { African } \\
\text { American }\end{array}$ & $\begin{array}{c}\text { Native } \\
\text { American }\end{array}$ & Hispanic & Other \\
\hline School 1 & 19 & $53 \%$ & $47 \%$ & $36.8 \%$ & $10.5 \%$ & $21.1 \%$ & $26.3 \%$ & $5.3 \%$ \\
\hline School 2 & 5 & $40 \%$ & $60 \%$ & $20.0 \%$ & $80.0 \%$ & --- & --- & --- \\
\hline School 3 & 10 & --- & $100 \%$ & $10.0 \%$ & $40.0 \%$ & $30.0 \%$ & $20.0 \%$ & --- \\
\hline School 4 & 57 & $37 \%$ & $63 \%$ & $80.7 \%$ & --- & $10.5 \%$ & $7.0 \%$ & $1.8 \%$ \\
\hline School 5 & 20 & $45 \%$ & $55 \%$ & $25.0 \%$ & $10.0 \%$ & $5.0 \%$ & $25.0 \%$ & $35.0 \%$ \\
\hline
\end{tabular}

Due to the small sample size $(n=8)$, the preliminary teacher survey data will not be presented here, but will be discussed when the second survey results allow comparison at the end of the 2002-2003 school year. 
Cronbach's coefficient alpha, which measured the lower bound for the internal consistency of the preliminary student responses, was calculated separately for the math and science subscales and additionally for the combined survey instrument. The resulting values are shown in Table 3. While the coefficient alpha can range from 0 to 1 , a value below .50 would suggest inconsistent responses. Our calculated alphas for the individual sections $(\alpha \geq .757)$ and for the combined instrument $(\alpha=.838)$ are well above the acceptable level, indicating that the students responded consistently, and therefore reliably, to the survey questions.

Table 3. Coefficient Alphas for ATA Student Experience Preliminary Surveys.

\begin{tabular}{|l|c|}
\hline ATA Student Survey Items & $\begin{array}{c}\text { Cronbach } \\
\text { Coefficient } \\
\text { Alpha }\end{array}$ \\
\hline Math (Items 1-23) & .757 \\
\hline Science (Items 24-46) & .800 \\
\hline Combined (Items 1-46) & .838 \\
\hline
\end{tabular}

\section{Conclusions}

Preliminary results from the student survey indicate that, on average, students 'sometimes' experienced authentic teaching practices in their math and science classrooms. In three of the five schools, the students indicated that the teaching behavior they previously experienced in their science courses has been slightly more 'authentic' than that experienced in their math courses. Additional preliminary data will be reported after all parental consent forms have been verified. At the end of the school year, comparisons will be made between the preliminary survey responses and the responses obtained after presentation of the ATA activities. The adapted instruments presented in this paper appear to provide a valid and reliable method to assess the character of the classrooms with respect to the presence of authentic teaching. Ultimately, we hope to see a significant increase in the averages at the end of the school year that would indicate an increase in authentic teaching in the participating classrooms and a positive impact of the ATA program.

\section{Bibliography}

1. Roelofs, E., \& Terwel, J. (1997). Questionnaire Authentic Pedagogy: Students. Ljubljana, The Netherlands: Department of Educational Studies and Center for Research on Cognition and Learning and the Educational Research Institute at Utrecht University.

2. National Science Foundation. (2002). Science and Engineering Indicators - 2002. Accessed on January 2, 2003 fromhttp://www.nsf.gov/sbe.srs/seind02/start.htm

3. National Center for Education Statistics. (2002). The Condition of Education. Accessed on January 2, 2003 from http://nces.ed.gov/programs/coe/index.asp.

4. Mullis, I. V. S., Martin, M. O., Gonzalez, E. J., Gregory, K. D., Garden, R. A., O’Connor, K. M., Chrostowski, S. J., \& Smith, T. A. (2000). TIMSS 1999 International Mathematics Report. Boston, MA: The International Study Center at Boston College and the International Association for Evaluation of Education Achievement. 
5. Rhoads, T. R., Nanny, M., \& O'Hair, M. J. (2002). “A Combined Engineering and Education Class at the University of Oklahoma: Preparing Authentic Science and Math Educators", in Proceedings of the 2002 American Society for Engineering Education Annual Conference \& Exposition, Session 2530, Montreal, Canada: A merican Society for Engineering Education.

6. Newmann, F. M., \& Associates (1996). Authentic Achievement: Restructuring Schools for Intellectual Quality. San Francisco: Jossey-Bass.

7. Roelofs, E., \& Terwel, J. (1999). "Constructivism and Authentic Pedagogy: State of the Art and Recent Developments in the Dutch National Curriculum in Secondary Education", Journal of Curriculum Studies, vol. 31 (2), pg. 201-227.

8. Franssen, H., \& Roelofs, E. (1997). Questionnaire Authentic Pedagogy: Teachers. Ljubljana, The Netherlands: Department of Educational Studies and Center for Research on Cognition and Learning and the Educational Research Institute at Utrecht University.

\section{TAMY L. FRY}

Tamy L. Fry is the Graduate Assessment Fellow for the Authentic Teaching Alliance at the University of Oklahoma. Currently a doctoral candidate in Industrial Engineering, Tamy has served as instructor and teaching assistant, and has also been involved in research projects for the National Science Foundation, the National Aeronautics and Space Administration, and the Federal Aviation Administration. Tamy received both a B.S. degree (1996) and an M.S. degree (1999) in Industrial Engineering from the University of Oklahoma. She plans to complete her dissertation, titled ‘Development And Validation Of Metrics To Evaluate Robotics Operator Performance', in May 2003.

\section{TERI REED RHOADS}

Teri Reed Rhoads is the Director of Engineering Education of the College of Engineering, the University of Oklahoma and an Assistant Professor of Industrial Engineering. Dr. Rhoads is actively involved in research with industry as well as with the National Science Foundation, the U. S. Department of Education, and the local school district Foundation. Her areas of interest are engineering education and assessment and K-20 integration, as well as quality engineering. She teaches Engineering Statistics, Quality Engineering and Regression. Dr. Rhoads received a B.S. degree in Petroleum Engineering from the University of Oklahoma in 1985, a Masters in Business Administration from the University of Texas of the Permian Basin in 1992, and a Ph.D. in Industrial Engineering from Arizona State University in 1999.

\section{MARK NANNY}

Mark Nanny is an Associate Professor of Civil Engineering and Environmental Sciences at the University of Oklahoma. He has a joint appointment between the College of Engineering and the Sarkeys Energy Center. Dr. Nanny teaches undergraduate and graduate environmental science and environmental chemistry courses. He has over 29 research publications in the area of environmental chemistry, and has edited a book on Nuclear Magnetic Resonance Spectroscopy in Environmental Chemistry. His educational research interests are in developing and teaching K-12 science curricula authentically as well as in assisting K-12 science teachers to develop their own authentic curricula.

\section{MARY JOHN O'HAIR}

Dr. O'Hair has been involved in educational leadership and school renewal issues for over 15 years. She has over 40 publications and 7 books on the topic, as well as has won numerous national and international awards for her achievements. In the past years, Dr. O'Hair has secured $\$ 677,980$ in external and internal funding for educational renewal research and development. Over the past three years, she has given keynote addresses to educational and government leaders in Finland, Germany, Australia, Northern Ireland, Kuwait, South Africa and Bulgaria. She has served as the Associate Dean for Graduate Studies and Research in the College of Education at OU, and is the founder of O.N.E. and the international Center for School Renewal and Democratic Citizenship. Dr. O'Hair has supervised seven Ph.D. students to completion.

\section{Appendix}




\section{Authentic Teaching Alliance \\ Student Experience Survey}

\section{Dear Student,}

This survey has been prepared by researchers at the University of Oklahoma who want to learn about your experiences with math and science in school. Your answers are very important to us, and will be used to help us create better, more interesting ways to teach these subjects. Please read each statement below, and then fill in the circle under the word that would make the statement the most truthful. Let's practice on the following question.

1. I eat spaghetti.

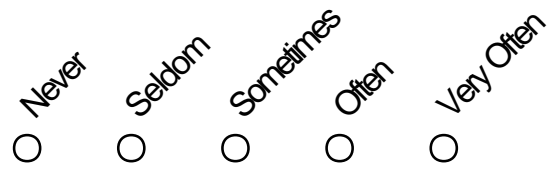

If you eat spaghetti several times a week, you would fill in the circle at the far right to respond "very often", but if you never eat spaghetti, you would fill in the circle under the word "never". This is not a test. There are no incorrect answers, since these are your honest opinions. You will not be graded on your answers. Completing this survey should take about twenty minutes of your time. All information will remain strictly confidential.

Name: (Please Print)

Birth Date:

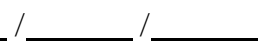

Grade:

$6 \quad 7$

8

9

10

$11 \quad 12$

For the following questions, circle the letter that best matches your response. Please circle only one letter per question.

1. What is your gender?
A. Male
B. Female

2. Which of the following best describes your ethnicity?
A. White
B. African American
C. Native American
D. Hispanic
E. Other

3. Which school are you currently attending?
A. Santa Fe South High School
D. John Marshall High School
B. Southeast High School
E. Emerson High School
C. Dibble High School
F. Roosevelt Middle School

Carefully read each of the statements on the following pages. Please answer each statement as honestly as you can by filling in the circle below the word that is closest to what you have experienced in your current math and science classes. Choose only one answer for each statement. If you make a mistake or change your mind, please erase the incorrect answer completely before selecting a new answer.

Thank you very much for your help! 
Please respond to the following statements

about your current math class.

1. My math teacher assigns problems that require me to find the information that is needed to solve them.

2. My math teacher tells me exactly which steps I must take to solve a mathematical problem.

3. My math teacher expects us to start work independently and to know what we are supposed to do.

4. I try to solve problems in my math textbook that are not assigned by the teacher.

5. My math teacher assigns problems that deal with topics from more than one chapter of the textbook.

6. I try to solve math problems on my own before I ask the teacher.

7. The problems in my math class deal with things from my real life outside of school.

8. My math teacher uses objects brought from home in our lessons.

9. My math teacher use examples that I understand from my own environment.

10. Certain math assignments are reviewed by people outside of my school.

11. I get math assignments that require me to collect data outside of the classroom.

12. I use my math knowledge to help me with tasks at home.

13. I understand the topics that are addressed in my math lessons.

14. My math teacher demonstrates how things at school and at home relate to math.

15. When completing math assignments, I think about the examples I know from my own environment.

16. Students in my math class ask questions about the things outside of school that have something to do with math.

17. When I am not in school, I recognize things that have something to do with math.

18. In my class, we discuss with one another the way a math problem can be solved.

19. In my math class, we talk about things we experience outside of class that are related to math. 
20. My math teacher expects me to cooperate with one or more

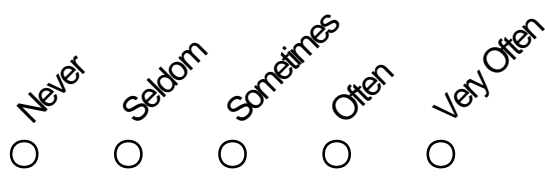
other students to solve certain math problems.

21. We are allowed to help one another when we do not understand the assignment.

22. Students in my math class help each other before we ask the teacher for help.

23. Students in my math class help review the work of other students.

Please respond to the following statements about your current science class.

24. My science assignments usually require me to do a lot of different things.

25. I sometimes do extra tasks in science class that are not assigned by the teacher.

26. In my science classes, I try to figure out the meaning of words before I ask the teacher.

27. In my science class, I only complete tasks which the teacher tells me to do.

28. We read about things from everyday life in my science class.

29. The science terms that we use appear in the material that we read.

30. We learn new science words by talking and reading.

31. I feel free to ask questions in my science class.

32. We have to memorize lists of science terms.

33. My science teacher uses things brought from home in our lessons.

34. My teacher mentions science news from newspaper and magazine articles.

35. Visitors come to my class to talk about science.

36. We get science assignments from people outside of our school.

37. In science class, we read and talk about topics from other school subjects.

38. My science assignments involve writing reports about science topics.
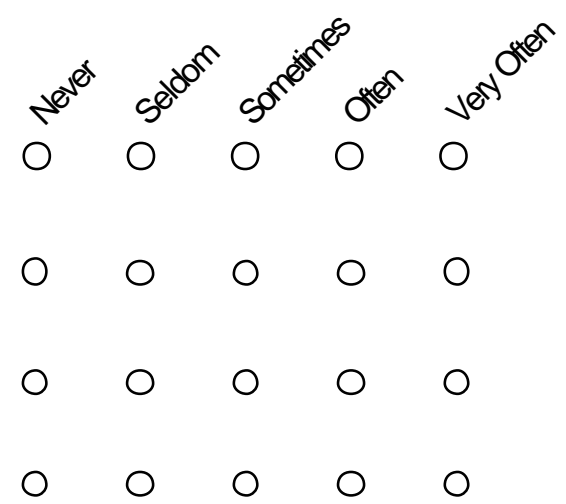

0000

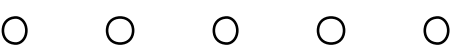

$0 \quad 0 \quad 0 \quad 0 \quad 0$

$\begin{array}{lllll}0 & 0 & 0 & 0 & 0\end{array}$

$0 \quad 0 \quad 0 \quad 0 \quad 0$

$\begin{array}{lllll}0 & 0 & 0 & 0 & 0\end{array}$

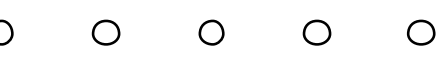

$\begin{array}{llllll}0 & 0 & 0 & 0 & 0\end{array}$

$\begin{array}{lllll}0 & 0 & 0 & 0 & 0\end{array}$
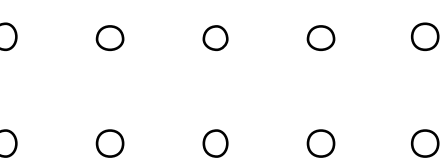

Proceedings of the 2003 American Society for Engineering Education Annual Conference \& Exposition Copyright $\left({ }_{0}\right.$ 2003, American Society for Engineering Education 


\section{Authentic Teaching Alliance Student Experience Survey}

39. We learn things about science from outside sources such as television, radio, and the Internet.

40. In my class, the students talk about science situations from their real life.

41. In class, I am free to express my opinion about science topics.

42. In my science class, I work with other students on projects or team assignments.

43. I have been asked to present the results of my work to the rest of the class.

44. We are encouraged to discuss things we have done or experienced that relate to science.

45. In science class, I am allowed to talk about things I like or things that I find interesting.

46. I like to read articles or watch television shows about science when I am out of school.

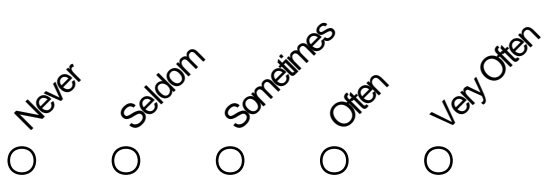

$\begin{array}{lllll}0 & 0 & 0 & 0 & 0\end{array}$

00000

$\begin{array}{lllll}0 & 0 & 0 & 0 & 0\end{array}$

00000

$\begin{array}{lllll}0 & 0 & 0 & 0 & 0\end{array}$

$\begin{array}{lllll}0 & 0 & 0 & 0 & 0\end{array}$

$\begin{array}{lllll}0 & 0 & 0 & 0 & 0\end{array}$

Thank you very much for participating!

Adapted from the Authentic Pedagogy Questionnaire developed by Roelofs \& Terwel (October 1997) at the Department of Educational Studies and Center for Research on Cognition and Learning and the Educational Research Institute at Utrecht University, Ljubljana, The Netherlands. 


\section{Authentic Teaching Alliance \\ Teacher Experience Survey}

Dear Teacher,

This survey was prepared by researchers at the University of Oklahoma who want to learn about regular classroom practices for teaching math and science in Oklahoma City secondary schools. Your answers are very important to us, and will help us determine which practices are feasible and which have been employed successfully. Some of the statements may seem idealistic to you, and far from your "daily" practice. In these cases, we would like to know the extent to which you support the teaching practices addressed in the statement. Filling out this form should require about 20 minutes of your time.

Please respond to the statements with respect to one particular math or science course that you teach. Most answers are based on a six-point scale, from "never" to "always", or from "fully disagree" to "fully agree". Fill in the circle below the word that would make the statement the most truthful.

We encourage you to answer as spontaneously and as honestly as you can. Choose only one answer for each statement. If you make a mistake or change your mind, please erase the incorrect answer completely before selecting a new answer.

Thank you very much for your help!

Name: (please print)

Course: $\begin{array}{llllllll}\text { Grade Level: } & 6 & 7 & 8 & 9 & 10 & 11 & 12\end{array}$

Please answer the following statements about your class.

1. I give my students tasks that can have different possible solutions.

2. My students have a say in determining the lesson content and procedures.

3. I respond to student questions with scaffolds rather than complete answers.

4. I give open-ended assignments and freedom in the means to carry them them out .

5. The course textbook allows me to design open-ended tasks that allow maximum freedom for students to work.

6. I ask my students to verbalize their thought processes when talking about their task performance.

7. I assign problems which require the students to collect information independently.

8. My students perform research in order to answer questions.

9. In assessing student work, I consider the solution process rather than simply the solution itself.

10. In grading, I place high value on the results of open-ended tasks that can result in different solutions.

11. When I introduce new content, I analyze students' personal experiences in detail.

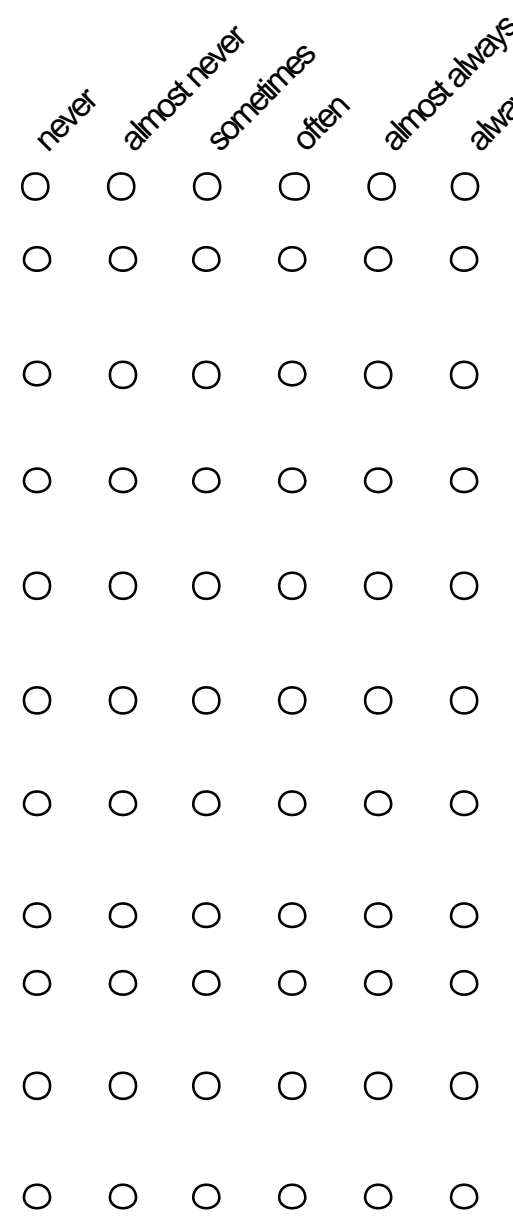


12. I choose my lesson topics from the students' personal world.

13. I enable my students to discuss their personal experiences that are related to the subject.

14. I use examples drawn from everyday life to explain subject matter.

15. I assign tasks whose requisite subject knowledge and skills are connected to the students' personal world.

16. I use students' expertise in addition to my own during lessons.

17. I choose lesson topics that students' have previously shown interest in.

18. I pay attention to recent developments in society.

19. Media (newspaper, television, radio, internet, etc.) play an important role in my lessons.

20. I give my students assignments which require them to present the results to outside experts.

21. The tests I give contain complex problems.

22. I pay attention to the relevance of subject matter for professional and personal purposes.

23. My students get many opportunities to apply their knowledge and skills by means of multimedia (simulations, graphical or communicative software, etc.)

24. I allow for students' personal opinions when addressing controversial problems.

25. I try to make connections with the content of other school subjects in my lessons.

26. I give homework assignments that refer directly to students' personal lives.

27. I give homework assignments that contain knowledge elements from different subjects.

28. During my lessons, students work together in groups on a collective task.

29. I prepare group tasks in such a way that students have to cooperate and communicate to complete them.

30. In my lessons, students take on different roles that mirror real life interactions (like a doctor and a client) in order to learn to communicate with one another.

31. I ask students to present the results of the assignment to others. 
32. I act as a facilitator during work on group tasks to foster independent learning.

33. Students are responsible for assessing their own progress during group tasks.

34. Both the students and I play a role in assessing the results of group tasks.

35. I intend to increase the number of assignments that are openended and can result in different solutions.

36. There is sufficient time in my class to enable the completion of open-ended tasks that can have different solutions.

37. I intend to offer students more choice in regarding lesson topics and lesson design.

38. I intend to increase the number of tasks that require the students to verbalize their thinking processes and strategies.

39. It is more important for the student to know the correct method to perform a task than to know the correct answers.

40. Students are able to perform independently.

41. Our school facilities, like the library, enable students to collect information independently.

42. The availability and quality of computers and software in our school enable the students to acquire and apply knowledge.

43. I intend to pay more attention to students' personal worlds when introducing new content.

44. The textbook I use encourages the selection of topics from everyday life.

45. The content and design of my lessons is highly dependent on the course textbook.

46. It is important to connect lesson topics to students' interests.

47. My lessons focus more on surviving in modern society than learning formal knowledge and skills.

48. Our school offers adequate possibilities to use media (newspaper, radio, television, internet, etc.)

49. With regard to tests, I intend to assign fewer but more complex problems related to students' personal worlds.
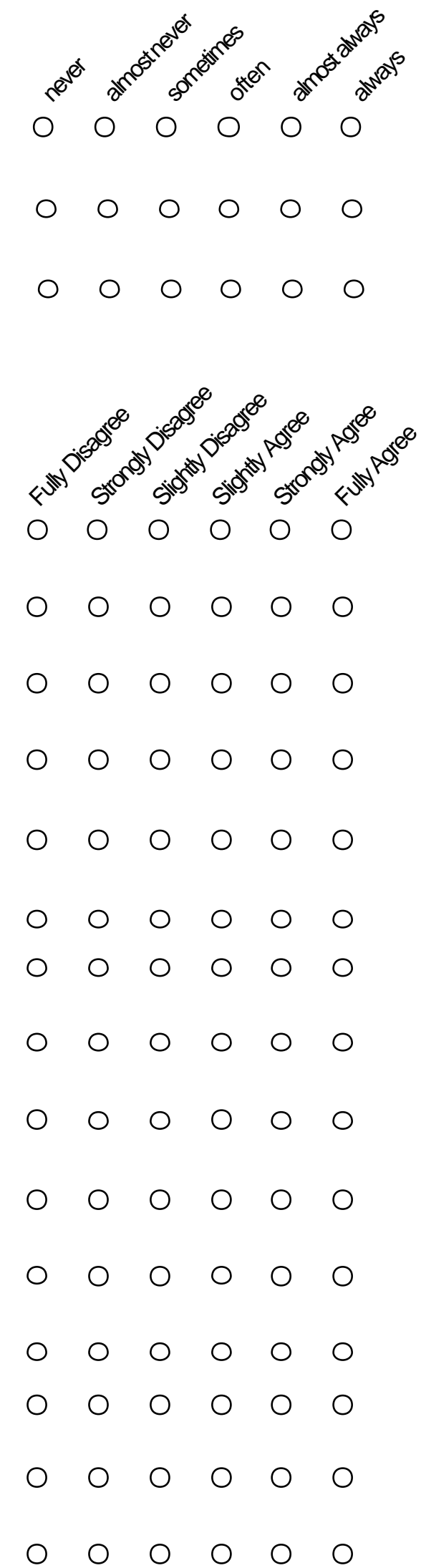

Proceedings of the 2003 American Society for Engineering Education Annual Conference \& Exposition Copyright (C) 2003, American Society for Engineering Education 


\section{Authentic Teaching Alliance \\ Teacher Experience Survey}

50. I intend to bring my students in contact with professionals (experts) at least once a year.

51. Relating subject matter to different school subjects is confusing for students.

52. Learning situations that integrate the content of school subjects (like projects) are needed at least three times a year.

53. I intend to raise the number of assignments that integrate the knowledge elements of different subjects.

54. Relating subject matter to different school subjects takes too much time.

55. Forms of integrated learning that combine knowledge of different school subjects are supported by school administration (flexible time table, cooperation between subject departments).
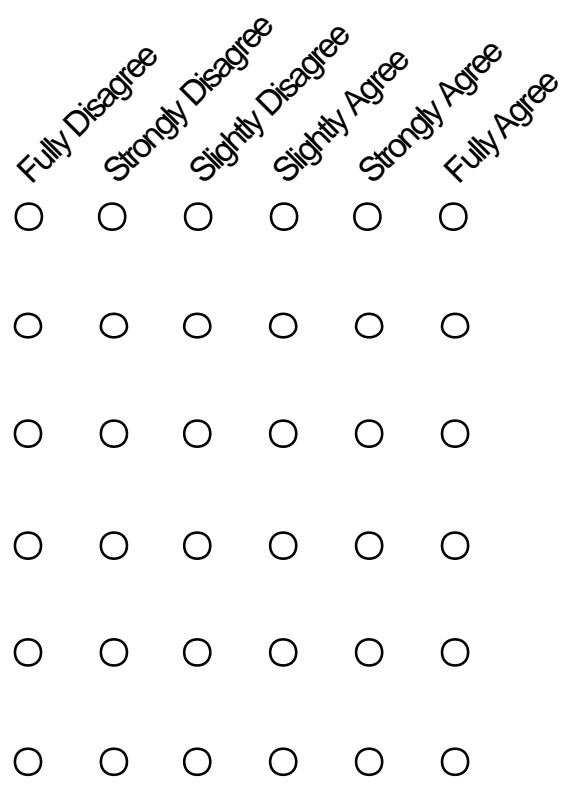

Thank you very much for your cooperation!

Adapted from the Authentic Pedagogy Questionnaire developed by Roelofs \& Franssen (October 1997) at the Department of Educational Studies and Center for Research on Cognition and Learning and the Educational Research Institute at Utrecht University, Ljubljana, The Netherland 